\title{
Analysis of clinical characteristics of macrophage capping protein (CAPG) gene expressed in glioma based on TCGA data and clinical experiments
}

\author{
QIANG FU ${ }^{1}$, MAHATI SHAYA ${ }^{2}$, SHAOSHAN LI $^{1}$, YALIKUN KUGELUKE ${ }^{1}$, \\ YISIREYILI DILIMULATI ${ }^{1}$, BO LIU $^{1}$ and QINGJIU ZHOU ${ }^{1}$ \\ Departments of ${ }^{1}$ Neurosurgery and ${ }^{2}$ Tumor Center, First Affiliated Hospital \\ of Xinjiang Medical University (XJMU), Urumqi, Xinjiang 830011, P.R. China
}

Received January 17, 2019; Accepted May 3, 2019

DOI: 10.3892/ol.2019.10396

\begin{abstract}
Macrophage capping protein (CAPG) genes were investigated based on The Cancer Genome Atlas (TCGA) database and clinical experiments. Glioblastoma (GBM) genes expression profiling chip of 529 disease samples and 10 normal samples selected from TCGA database were used for analysis, 25 brain glioma tissue samples and 15 normal brain tissues were collected in the Department of Neurosurgery of the First Affiliated Hospital of Xinjiang Medical University in China from 2016 to 2017 to analyze CAPG genes. TCGA results showed that the expression level of CAPG genes in GBM was higher than that in normal tissues, and the expression level of men, aged over 46 years and high grade gliomas in pathological stages was higher than that of women, aged $\leq 46$ and low grade gliomas in pathological stages, and the survival time of high expression was shorter than that of low expression. The expression level of CAPG in glioma tissues was higher than that in normal tissues, and the expression level of CAPG in males was higher than that in females, as males had lymphatic transfer and low differentiation compared with females, but the expression level was not related to age. Survival analysis showed that higher expression level indicated shorter survival time, they were positively correlated. The expression of CAPG in glioma is high, and it is highly expressed with the severity of the disease, and it is also obviously related to the prognosis. Therefore, CAPG could be used as a biomarker for pathological grade and prognosis in glioma. However, the related studies are not consistent on the expression of different sex and ages, so further study is needed.
\end{abstract}

Correspondence to: Dr QingJiu Zhou, Department of Neurosurgery, First Affiliated Hospital of Xinjiang Medical University (XJMU), 137 Liyushan street, Xinshi, Urumqi, Xinjiang 830011, P.R. China

E-mail: eq64ec@163.com; zhouqingjiu007@163.com

Key words: macrophage-capping protein, pathological grade, lymphatic transfer, age

\section{Introduction}

Glioblastoma (GBM) is a solid invasive tumor originating from the supporting cells of the central nervous system $(1,2)$, accounting for 40 to $50 \%$ of intracranial tumors. According to its growth pattern, it is divided as diffuse glioma and localized glioma. The former is common in adults and has a higher degree of malignancy (3-6). Most patients with gliomas have moderate advanced stages when they seek medical advice. Surgical treatment is the main routine treatment $(7,8)$, but the effect is not ideal. Studies show that the median survival time is only 12-15 months, and the 2- and 5-year survival rates are 20 and $5 \%$, respectively $(9,10)$. Therefore, early diagnosis and treatment, play an important role in improving the survival rate of glioma patients. CAPG is a member of the gelysin superfamily. Studies have shown that the expression of CAPG in tumor cells is significantly higher than that in normal tissues (11). However, there are few related studies on the expression in glioma. The Cancer Genome Atlas (TCGA) is a joint genome of the National Cancer and Oncology Institute (NCI) and the National Human Genome Research Institute (NHGRI) that uses large-scale genome sequencing to map all human cancers. The variogram was drawn and has been systematically analyzed, aiming to find all the minor mutations in carcinogenic and anti-oncogenic genes. This study analyzed the TCGA gene expression profiling chip and RNAseq data in combination with tumor tissues of patients with clinical glioma, explored the clinical expression characteristics of CAPG in human glioma, and provided new ideas and methods for early diagnosis and treatment of glioma.

\section{Materials and methods}

\section{Data analysis method based on TCGA}

Selection of data. The gene expression profiling chip RNA-seq level 3 data and pathological data of GBM in TCGA database were downloaded and sorted, which contained 529 disease samples and 10 normal samples, which were directly used to analyze differential genes. In this study, 515 samples of low grade gliomas (LGG) and 152 samples of high grade gliomas (HGG) were selected. 
Table I. Performance of CardGene.

\begin{tabular}{lcccccc}
\hline Gene & FC & P-value & FDR & Total samples & Normal samples & Cancer samples \\
\hline CAPG & 5.953 & $7.920 \mathrm{E}-15$ & $1.104 \mathrm{E}-13$ & 558 & 10 & 548 \\
\hline
\end{tabular}

Some samples measured multiple sets of data. The actual number of downloaded files is more than the number of samples. The number of samples here is actually the total number of files. CAPG, macrophage capping protein.

Table II. CardGene genetic information.

\begin{tabular}{|c|c|c|c|c|c|}
\hline Gene ID & Gene name & $\begin{array}{l}\text { Number } \\
\text { of transcripts }\end{array}$ & $\begin{array}{c}\text { Number } \\
\text { of Pubmed documents }\end{array}$ & $\begin{array}{l}\text { Novoseek disease } \\
\text { relationships for the gene }\end{array}$ & $\begin{array}{l}\text { MalaCard disease } \\
\text { relationships for the gene }\end{array}$ \\
\hline 822 & CAPG & 6 & 54 & 0 & 0 \\
\hline
\end{tabular}

CAPG, macrophage capping protein.

The study was approved by the Ethics Committee of the First Affiliated Hospital of Xinjiang Medical University (Urumqi, China). Patients who participated in this research had complete clinical data. The signed informed consents were obtained from the patients or the guardians.

Obtaining differential genes. Our data was normalized and t-test was done using the Affy and Limma packages in the $\mathrm{R}$ language, and then the data was filtered according to $\mathrm{P}<0.05$ and $\mid \mathrm{FCl} \geq 2$. The performance of CardGene is shown in Table I.

HCS screening. The number of target genes was reduced by the following criteria: i) the genes reported in relevant SCI papers were removed; ii) removing multiple transmembrane protein genes; iii) removing undefined gene annotation (e.g., with an open reading frame in the description); iv) removing the number of PubMed articles more than 60; and v) removing filtered gene from existing experimental data in key gene databases. The relevant data sources are highly reliable gene disease databases. And the final list of genes was randomly condensed to determine which list of genes to be analyzed (Table II).

\section{Clinical experimental methods}

Organization of acquisition. From 2016 to 2017, 25 cases of glioma tissue specimens diagnosed in the Neurosurgery Department of the First Affiliated Hospital of Xinjiang Medical University were collected as the experimental group, aged from 21 to 58 years (mean 43.12 \pm 10.12 ), 15 males and 10 females. None of the patients received anti-tumor therapy such as chemotherapy, radiotherapy or biological therapy before operation, and each case was confirmed by complete clinical and pathological data. Fifteen normal brain tissue specimens were collected from traumatic decompression surgery in the same period as the control group. All specimens were collected within half an hour after isolation and stored in a refrigerator at $-80^{\circ} \mathrm{C}$.

Experimental methods. Total RNA was extracted from the glioma tissue using the TRIzol reagent (Invitrogen Life Technologies, Inc.; Thermo Fisher Scientific, Inc., Waltham,
MA, USA). RT-PCR was used to evaluate the expression of CAPG in the cell lines. The cDNA was obtained by reverse transcription kit and stored at $-20^{\circ} \mathrm{C}$ for later use. The total RNAs were extracted by RNA isolation kit (GE Healthcare, Munich, Germany), and the cDNAs were prepared by using transcriptor first strand cDNA synthesis kit (Roche Diagnostics GmbH, Mannheim, Germany), carried out on the ABI 7500, SYBR Green system (Bio-Rad Laboratories, Inc., Hercules, CA, USA). The conditions of qPCR were as follows: One cycle at $50^{\circ} \mathrm{C}$ for $2 \mathrm{~min}$ and $95^{\circ} \mathrm{C}$ for $10 \mathrm{~min}$ and followed by 40 cycles of denaturation at $95^{\circ} \mathrm{C}$ for $15 \mathrm{sec}$ and annealing extension at $55^{\circ} \mathrm{C}$ for $1 \mathrm{~min}$. The primers used included the following: CAPG F: CGAACACTCAGGTGGAGATT and R: TCCAGTCCTTGAAAAATTGC; GAPDH F: TGCACC ACCAACTGCTTAGC and R: GGCATGGACTGTGGTCAT GAG. After amplification, the melting curve was analyzed to determine the specificity of the PCR products, and the threshold cycle values of CAPG and GAPDH were obtained. The relative quantity of CAPG was calculated by $2^{-\Delta \Delta C q}$ as the reference (12).

Immunohistochemistry. Tissues were harvested and fixed in $10 \%$ formalin at room temperature for one week, then embedded in paraffin, from which $4 \mu \mathrm{m}$-thick sections were made. The slides were incubated with $3 \%$ hydrogen peroxide to quench endogenous peroxidase activities. After heat induced antigen retrieval, the specimens were blocked with 5\% normal goat serum (ImmunoReagents Inc., Raleigh, NC, USA) for $1 \mathrm{~h}$ at room temperature, and incubated with antibodies against $\mathrm{CAPG}$ (cat. no. ab155688; dil, 1:50) at $4^{\circ} \mathrm{C}$ overnight, and donkey antigoat IgG-HRP secondary antibody (cat. no. ab205723; dil, 1:200) both from Abcam (Cambridge, UK). Slides underwent color development with 3-3'-diaminobenzidine (DAB) and were counterstained with hematoxylin. Photomicrographs were taken with a light Olympus microscope BX51 (Olympus Corporation, Tokyo, Japan). The staining intensity was scored on a scale of 0 to 3 as negative, weak, medium and strong, respectively. The stained area, which was calculated as the percentage of positively stained cells relative to the total cells, was scored on a 
Table III. Analysis of significant differences in gene expression levels at various clinical data levels.

\begin{tabular}{lccr}
\hline & \multicolumn{2}{c}{ Expression levels of objective gene } & \\
\cline { 2 - 3 } Variables & Low & High & P-value \\
\hline Age & & & $<0.001$ \\
$\leq 46$ & $224(65.88)$ & $116(34.12)$ & \\
$>46$ & $110(33.64)$ & $217(66.36)$ & \\
Sex & & & 0.037 \\
$\quad$ Male & $179(46.61)$ & $205(53.39)$ & \\
Female & $155(54.77)$ & $128(45.23)$ & \\
Pathological stage & & & $<0.001$ \\
$\quad$ LGG & $324(62.91)$ & $191(37.09)$ & \\
HGG & $10(6.58)$ & $142(93.42)$ & \\
\hline
\end{tabular}

LGG, low grade gliomas; HGG, high grade gliomas.

scale of 0 to $4: 0(0 \%), 1(1-25 \%), 2$ (26-50\%), $3(51-75 \%)$ and $4(76-100 \%)$. The overall score was calculated by multiplying the intensity score and the staining area score. Samples were categorized into four grades: An overall score equal to 0 was graded as '-'; an overall score equal to 1,2,3 or 4 was graded as '+'; an overall score equal to $5,6,7$ or 8 was graded as ' ++ '; an overall score equal to $9,10,11$ or 12 was graded as ' +++ '. The stained tissue sections were analyzed by two pathologists without any knowledge regarding the patient clinical information. Based on the immunohistochemical grades, the patients were divided into two groups: the high expression group, which included patients with grades '++' or ' +++ ', and the low expression group, including patients graded as '-' or ' + '.

Data collection. The data of age, sex, ethnicity, surgical approach, tissue type of tumor, metastasis condition, pathological staging and follow-up for one year of survival were collected.

Statistical analysis. Data was entered in excel, and analyzed by R language. Kolmogorov-Smirnov test was used to test the normality of relative quantity of CAPG mRNA. The measurement data were analyzed by t-test and variance analysis, and the counting data were tested by Chi-square test. Spearman's correlation was used for correlation analysis, and log-rank test was used to test the statistical significance of survival analysis. Kaplan-Meier was used in order to generate the curves. The test level was $0.05, \mathrm{P}<0.05$ was considered to indicate a statistically significant difference.

\section{Results}

\section{Results of TCGA data analysis method}

Results of CardGene analysis. Previous studies have yielded differential results for normal and human glioma CAPG genes expression. The vertical coordinates shown below were the corresponding signal values of genes in the expression microarray, and the transverse axis was from normal and cancer tissues, respectively. Fig. 1, clearly shows the difference

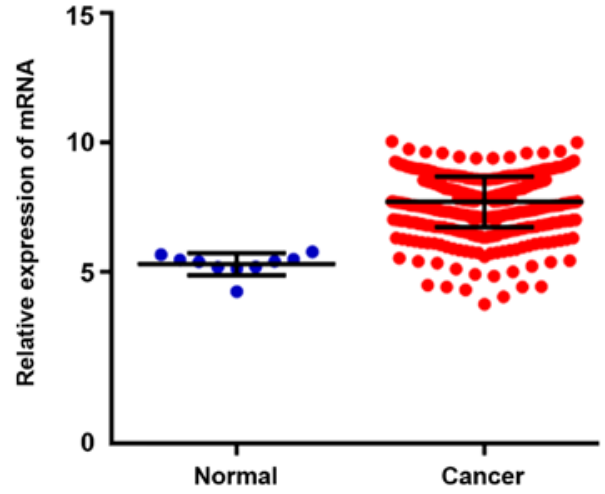

Figure 1. Gene expression of CAPG between normal and human glioma. The gene expression profiling data of 529 glioblastoma tissues and 10 normal samples in TCGA database were chosen to re-analyze the mRNA levels of CAPG. $P<0.05$. TCGA, The Cancer Genome Atlas; CAPG, capping protein gene.

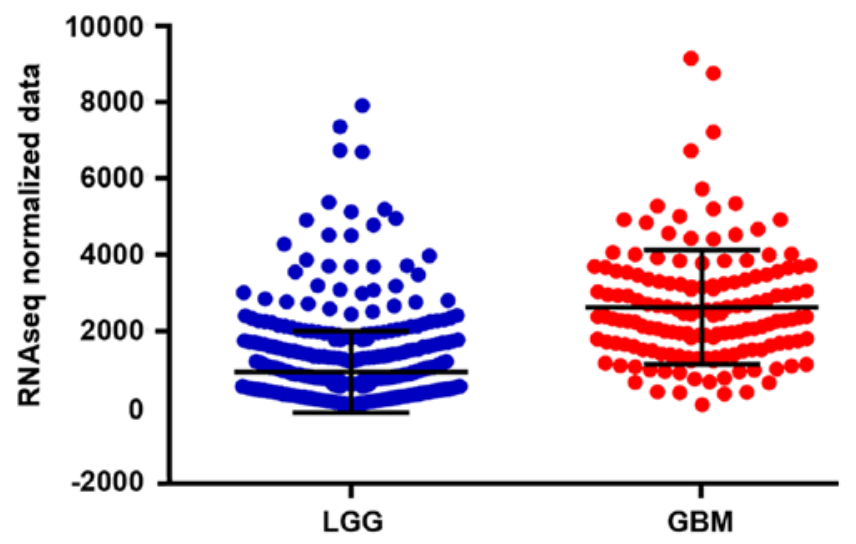

Figure 2. Gene distribution of CAPG between different expression levels. In total 515 samples of LGG and 152 samples of HGG were selected, and the expression of CAPG is shown. LGG, low grade gliomas; HGG, high grade gliomas; CAPG, capping protein gene.

of gene expression distribution between the two, the expression of CAPG in cancer tissue was higher than that in normal tissue $(\mathrm{P}<0.05)$.

Analysis of significant differences in gene expression levels at various clinical data levels. The results of this study showed that the expression of CAPG was significantly different in patients with different age, sex and pathological stage, suggesting that the expression of CAPG might be related to the above-mentioned clinical pathological stage. The results of statistical analysis are shown in Table III, and the high expression rate of CAPG aged $>46$ years, male and pathological stages of HGG were higher than that aged $<46$, female and pathological stages of LGG. Pathological information is shown in Fig. 2.

Correlation between gene expression level and clinical data. The results of correlation analysis showed that the expression level of CAPG was significantly correlated with age, sex and pathological stage of the patients, and was positively correlated with age and pathological stage, and negatively correlated with sex $(\mathrm{P}<0.001$; Table IV). 
Table IV. Correlation between gene expression level and clinical data.

\begin{tabular}{lcccc}
\hline Variables & $\begin{array}{c}\text { Expression } \\
\text { level }\end{array}$ & Age & Sex & $\begin{array}{c}\text { Pathological } \\
\text { stage }\end{array}$ \\
\hline Expression level & & & & \\
$\quad$ r & 1.000 & 0.322 & -0.081 & 0.473 \\
P-value & - & $<0.001$ & 0.037 & $<0.001$ \\
Age & & & & \\
r & 0.322 & 1.000 & -0.011 & 0.397 \\
P-value & $<0.001$ & - & 0.785 & $<0.001$ \\
Sex & & & & \\
r & -0.081 & -0.011 & 1.000 & -0.083 \\
P-value & 0.037 & 0.785 & - & 0.032 \\
Pathological stage & & & & \\
r & 0.473 & 0.397 & -0.083 & 1.000 \\
P-value & $<0.001$ & $<0.001$ & 0.032 & - \\
\hline
\end{tabular}

0 for men and 1 for women were set in the statistical process.

Table V. Level of gene expression and survival test of clinical data.

\begin{tabular}{lccc}
\hline Variables & Total no. & Events & P-value \\
\hline Expression & & & \\
HGG & 332 & 76 & $<0.001$ \\
LGG & 332 & 169 & \\
Total & 664 & 245 & \\
\hline
\end{tabular}

HGG, high grade gliomas; LGG, low grade gliomas.

Univariate survival analysis. The results of survival analysis showed that the expression level of CAPG had a significant effect on the survival time of patients, and the prognosis of patients with higher expression level of CAPG was poor. The difference of log-rank test was significant $(\mathrm{P}<0.05$; Table V and Fig. 3).

\section{Clinical experimental results}

Normality test. Kolmogorov-Smirnov test was used to test the normality of relative quantity of CAPG mRNA, Z=3.211, $\mathrm{P}<0.001$, which is a skewed distribution.

Expression of CAPG in glioma tissues. The results of IHC staining showed that the expression of CAPG in LGG and HGG tissues was higher than that in normal tissues (Fig. 4A), the difference was statistically significant $(\mathrm{P}<0.05$; Fig $4 \mathrm{~B})$.

Characteristics of CAPG $m R N A$ expression in glioma. The results showed that the expression of CAPG mRNA in glioma was different among different sex, lymph node metastasis and pathological tissue types. The expression of CAPG in male, lymphatic metastasis and poorly differentiated tumors

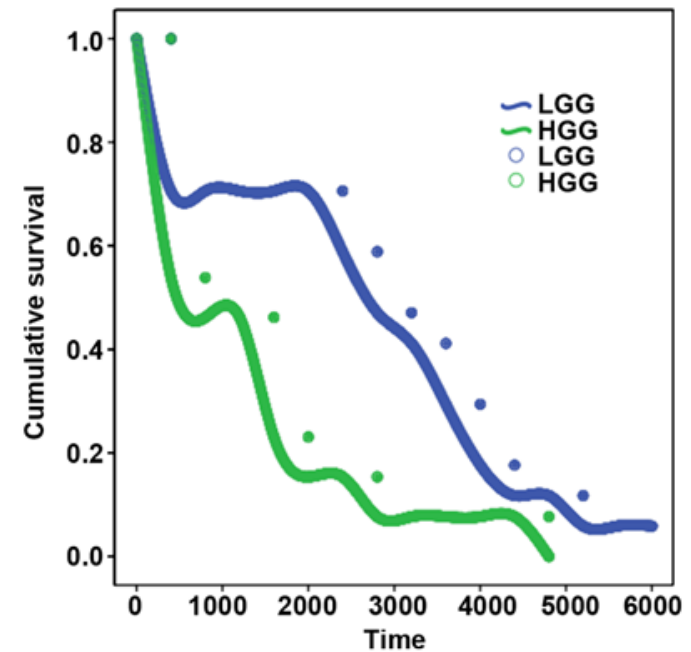

Figure 3. Survival time of patients with different pathological stage. In total 515 patients of LGG and 152 patients of HGG were selected, and their differences of the survival time was determined (log-rank test, $\mathrm{P}<0.05$ ) LGG, low grade gliomas; HGG, high grade gliomas.

\section{A anti-CAPG antibody}

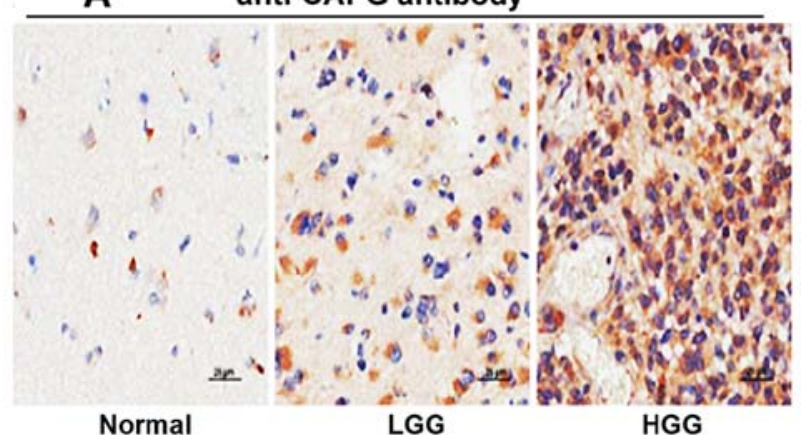

B

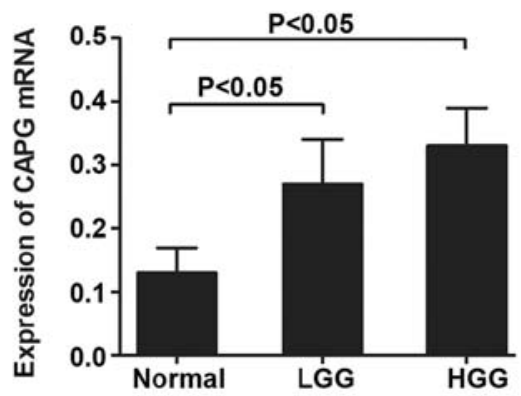

Figure 4. Expression levels of CAPG mRNA in different tissues. (A) IHC staining of the expression of CAPG in normal, LGG and HGG tissues. (B) The mRNA levels of CAPG was examined. CAPG, capping protein gene; IHC, immunohistochemistry; LGG, low grade gliomas; HGG, high grade gliomas.

was higher than that in female, non-lymphatic metastasis and highly differentiated tumors, and the difference was statistically significant $(\mathrm{P}<0.005$; Table VI).

Analysis of CAPG mRNA and survival time. Among the patients who were followed up for one year, 11 died and 14 survived. The expression level of CAPG had a significant 
Table VI. Expression of CAPG mRNA in clinic.

\begin{tabular}{lccc}
\hline Variables & Relative expression & \\
\hline Age & of CAPG mRNA & P-value \\
$<50$ & & & \\
$>50$ & 14 & $0.30(0.17,0.45)$ & 0.143 \\
Sex & 11 & $0.32(0.15,0.47)$ & \\
$\quad$ Male & & & \\
$\quad$ Female & 15 & $0.33(0.15,0.41)$ & 0.004 \\
Ethnicity & 10 & $0.29(0.11,0.57)$ & \\
$\quad$ Han & & & \\
$\quad$ Minorities & 19 & $0.30(0.15,0.58)$ & 0.209 \\
Lymphatic metastasis & 6 & $0.32(0.13,0.51)$ & \\
$\quad$ Have & & & \\
$\quad$ No & 12 & $0.35(0.20,0.50)$ & $<0.001$ \\
$\quad$ Pathological types & 13 & $0.25(0.13,0.62)$ & \\
$\quad$ HGG & & & \\
$\quad$ LGG & 10 & $0.33(0.21,0.51)$ & 0.013 \\
$\quad$ Normal & 15 & $0.27(0.15,0.39)$ & \\
\end{tabular}

CAPG, capping protein gene; HGG, high grade gliomas; LGG, low grade gliomas.

Table VII. The result of survival test.

\begin{tabular}{lcccc}
\hline Variables & Total no. & Event & Log-rank & P-value \\
\hline $\begin{array}{l}\text { Expression } \\
<0.3\end{array}$ & 12 & 1 & 15.3321 & $<0.001$ \\
$>0.3$ & 13 & 10 & & \\
Total & 664 & 245 & & \\
\hline
\end{tabular}

effect on the survival time of patients. Patients with higher expression levels of CAPG had shorter survival time, and there was a significant difference in log-rank test $(\mathrm{P}<0.001)$. Pearson's correlation analysis of survival time and CAPG expression showed a negative correlation between survival time and CAPG ( $\mathrm{r}=-0.792, \mathrm{P}<0.001$; Table VII and Fig. 5).

Multi-factor analysis. The statistically significant index was used in Table II as the independent variable, and the expression of CAPG mRNA was logarithmically transformed (normalized) and then used as a dependent variable for multiple linear regression analysis, $\alpha$ in $=0.05$, $\alpha$ out $=0.01$. Stepwise regression analysis showed that lymphatic metastasis and histopathological type were independent factors affecting the expression of CAPG. The expression of CAPG in tumor tissues with lymphatic metastasis was higher than that in non-lymphatic metastatic tissues, and the lower the differentiation degree, the higher the expression of CAPG in tumor tissues with lymphatic metastasis. The difference was statistically significant, as shown in Table VIII.
Table VIII. Analysis of multiple linear regression.

\begin{tabular}{lcccc}
\hline Index & B & S.E & Beta & P-value \\
\hline Variable & 48.321 & 10.098 & & $<0.001$ \\
Sex & 10.991 & 9.032 & 0.435 & 0.213 \\
Lymphatic metastasis & -8.123 & 1.276 & 0.389 & $<0.001$ \\
Tissue type & 11.587 & 3.121 & 0.320 & 0.005 \\
\hline
\end{tabular}

Assignment: sex: male $=0$, female $=1$; lymphatic metastasis, with $\pi=0$, without $=1$; tissue type: normal $=0$, highly differentiated $=1$, poorly differentiated $=2$.
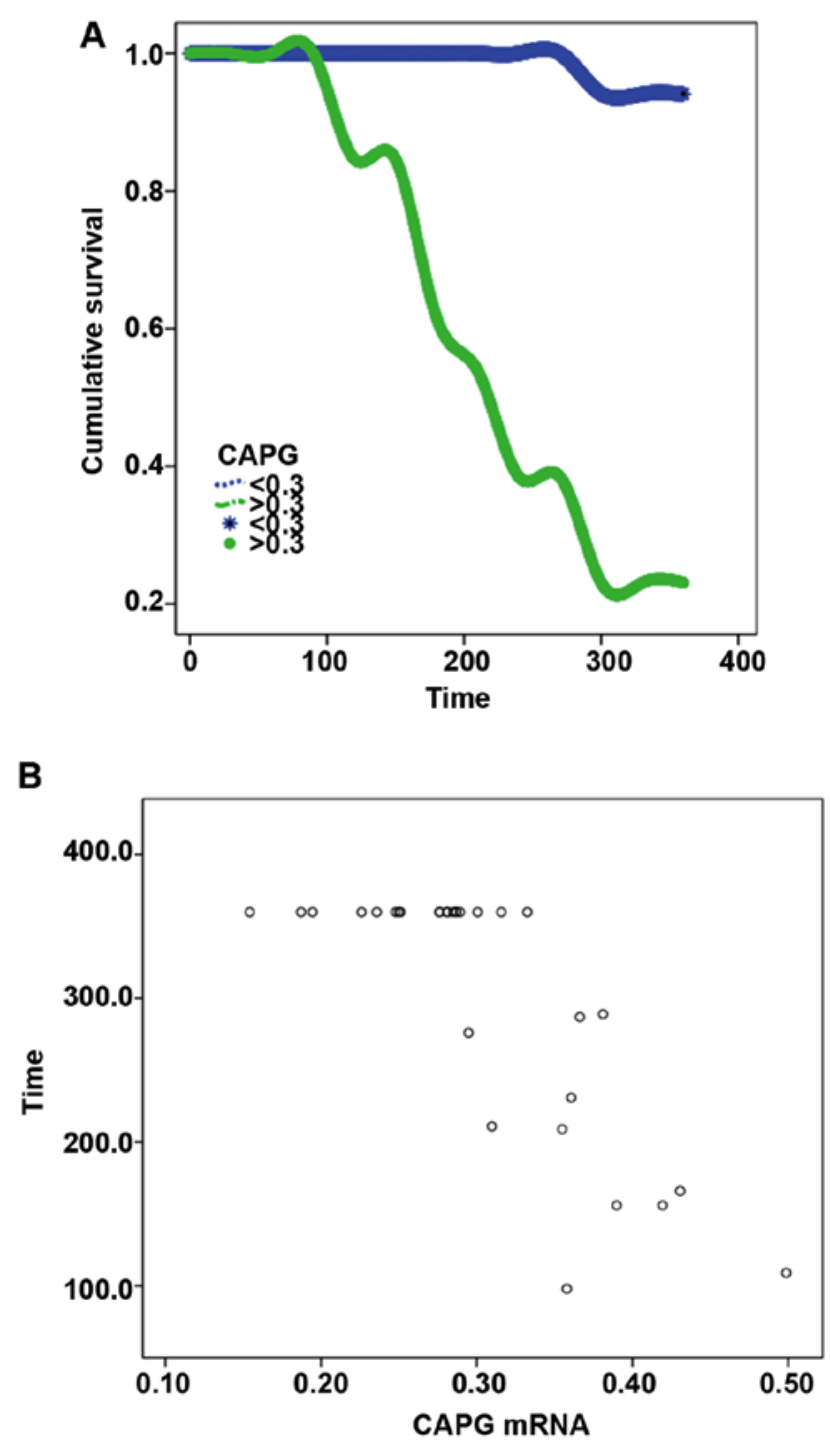

Figure 5. Survival analysis and scatter diagram. (A) The correlation between CAPG expression and overall survival was examined in glioma patients (log-rank test, $\mathrm{P}<0.001$ ). (B) Pearson's correlation analysis of survival time and CAPG expression $(r=-0.792, P<0.001)$. CAPG, capping protein gene.

\section{Discussion}

Glioma is a common malignant tumor in the central nervous system, the morbidity is approximately $80 \%$ in the alignant tumors of brain. In intracranial malignant tumors, the GBM, 
which has the highest degree of malignancy, is one of the main causes of death. In recent years, the important role of cytoskeleton protein in tumor prognosis has been paid increasing attention, and cytoskeleton recombination is an important factor in invasion and metastasis of tumor cells $(13,14)$. CAPG is an important actin-binding protein, which was first found in human alveolar macrophages, and it is $\mathrm{Ca}^{2+}$ dependent actin-binding protein which is composed of 348 amino acids. It regulates the length of actin by capping and cutting microfilaments to promote the cross-linking of actin and the reorganization of the cytoskeleton (15). Therefore, CAPG might be a new potential factor to promote tumorigenesis and as a new target of anti-cancer drugs.

Various biological public databases have been applied with the advent of the big data era, such as the Gene Expression Omnibus (GEO) gene expression database, the Survey Epidemiology and End Results (SEER) database and the gene Atlas of TCGA database (16-18). TCGA is led by the NCI, and is a major project to conquer cancer in USA. It systematically provides sequencing and chip data of cancer genomics, provides a large genomic and clinical data for researchers in cancer basic science and gene transfer chemistry, and provides a large data basis for mining meaningful genomes and discovering biological mechanisms affecting tumor occurrence, development, differentiation and metastasis.

Our study aimed to analyze the data of gene expression profile-chip and pathology which were selected from 529 disease samples and 10 normal GBM in TCGA database. The results showed that the expression of CBM CAPG gene was higher than that in normal tissues. A further analysis of the clinical data showed that the expression of CAPG in males with the high expression rate of CAPG aged $>46$ years and pathological stages of HGG were higher than that in females aged $\leq 46$, with pathological stages of LGG. The results of correlation analysis also showed that CAPG expression level was positively correlated with age and pathological stage, and negatively correlated with sex. Survival analysis showed that the expression level of CAPG had a significant impact on the survival time, and patients with higher expression level of CAPG had poor prognosis.

Above are the results of TCGA data analysis. However, there would be various kinds of gene expression due to different countries, regions and races. In order to further verify the clinical features of CAPG expression in GMB tumor tissues, we randomly selected 25 tumor tissues of glioma patients from neurosurgery department in the First Affiliated Hospital of XJMU of China as the experimental group, and 15 normal brain tissues which underwent traumatic decompression surgery as the control group. RT-qPCR showed that the expression of CAPG mRNA in glioma tissues was higher than that in normal tissues, and the expression level in males with lymphatic metastasis and low differentiation was higher than that in females, without lymphatic metastasis and high differentiation. The results of survival analysis after one year's follow-up showed that the expression level had a significant impact on the survival time. The survival time of patients with higher expression level was short, and Pearson correlation analysis showed that there was negative correlation between the survival time and CAPG.

The results above showed that CAPG was highly expressed in glioma tumor tissues. Resent studies show that CAPG are highly expressed in lung cancer (19), pancreatic cancer (20), breast cancer $(21,22)$, prostate cancer (23) and gastric cancer $(24,25)$, and are closely related with metastasis-CAPG is obviously highly expressed in tumor tissues with metastasis. The expression level of CAPG in glioma might be related to age, sex, metastasis, pathological stage and tissue type. There are two studies on glioma which could be retrieved at present. Xing and Zeng (26) reported a study in 2015, on tissue samples from 90 gliomas and 90 adjacent brain tissues and 5 pairs with grade I-IV gliomas. RNA was extracted and expressed on Affymetrix Human Gen U133 Plus 2.0 Array. The results showed that 1,725 genes were differentially expressed in glioma, and their expression levels were related to pathological grade, and were not related to age and subtype, and the mRNA expression level of CAPG was increasing from stage II to IV. Thus proving that CAPG protein expression in human glioma was related. The survival analysis also showed that patients with high expression of CAPG had a short survival time, which was consistent with our study. Yun et al (27) published a study in 2018, which was based on the TCGA database. It also pointed out that the mRNA and protein levels of CAPG in human glioma were significantly increased, and the high expression of CAPG was an independent prognostic factor for poor prognosis. Multivariate COX analysis showed that the median survival was short in glioma patients over 60 years of age with high CAPG expression. The results showed that overall survival was shortened under the high expression of CAPG.

As can be seen from the above studies, the expression of CAPG in glioma is indeed high, and it is highly expressed with the severity of the disease, and it is obviously related to the prognosis. Therefore, CAPG could be used as a biomarker for pathological grade and prognosis of glioma. However, the related studies are not consistent on the expression of different sex and ages, and further study is needed.

\section{Acknowledgements}

Not applicable.

\section{Funding}

No funding was received.

\section{Availability of data and materials}

The datasets used and/or analyzed during the present study are available from the corresponding author on reasonable request.

\section{Authors' contributions}

QF, MS and QZ were responsible for RT-qPCR. SL and YK collected and analyzed general data of patients. YD and BL were responsible for statistical analysis. QF wrote the manuscript. The final version was read and approved by all the authors.

\section{Ethics approval and consent to participate}

The study was approved by the Ethics Committee of the First Affiliated Hospital of Xinjiang Medical University (Urumqi, 
China). Patients who participated in this research had complete clinical data. The signed informed consents were obtained from the patients or the guardians.

\section{Patient consent for publication}

Not applicable.

\section{Competing interests}

The authors declare that they have no competing interests.

\section{References}

1. Oh J, Kim Y, Che L, Kim JB, Chang GE, Cheong E, Kang SG and Ha Y: Regulation of cAMP and GSK3 signaling pathways contributes to the neuronal conversion of glioma. PLoS One 12: e0178881, 2017.

2. Yu X, Sun NR, Jang HT, Guo SW and Lian MX: Associations between EGFR gene polymorphisms and susceptibility to glioma: a systematic review and meta-analysis from GWAS and case-control studies. Oncotarget 8: 86877-86885, 2017.

3. Zhao P, Chen A, Qi Q, Zhou W, Feng Z, Wang J, Yang N, Li X, Wang J, Huang Q, et al: Impact of VEGFA polymorphisms on glioma risk in Chinese. Oncotarget 8: 83712-83722, 2017.

4. Gao L, Chen B, Li J, Yang F, Cen X, Liao Z and Long X: $\mathrm{Wnt} / \beta$-catenin signaling pathway inhibits the proliferation and apoptosis of U87 glioma cells via different mechanisms. PLoS One 12: e0181346, 2017.

5. Abdul AURM, De Silva B and Gary RK: The GSK3 kinase inhibitor lithium produces unexpected hyperphosphorylation of $\beta$-catenin, a GSK3 substrate, in human glioblastoma cells. Biol Open 7: 7, 2018.

6. Biau J, Chautard E, De Schlichting E, Dupic G, Pereira B, Fogli A, Müller-Barthélémy M, Dalloz P, Khalil T, Dillies AF, et al: Radiotherapy plus temozolomide in elderly patients with glioblastoma: A 'real-life' report. Radiat Oncol 12: 197, 2017.

7. Chen Q, Ye L, Fan J, Zhang X, Wang H, Liao S, Song P, Wang Z, Wang S, Li Y, et al: Autophagy suppression potentiates the anti-glioblastoma effect of asparaginase in vitro and in vivo. Oncotarget 8: 91052-91066, 2017.

8. Andronesi OC, Esmaeili M, Borra RJH, Emblem K, Gerstner ER, Pinho MC, Plotkin SR, Chi AS, Eichler AF, Dietrich J, et al: Early changes in glioblastoma metabolism measured by MR spectroscopic imaging during combination of anti-angiogenic cediranib and chemoradiation therapy are associated with survival. NPJ Precis Oncol: Jun 12, 2017 (Epub ahead of print). doi: 10.1038/ s41698-017-0020-3.

9. Costa RB, Costa R, Kaplan J, Cruz MR, Shah H, Matsangou M and Carneiro B: A rare case of glioblastoma multiforme with osseous metastases. Case Rep Oncol Med 2017: 2938319, 2017.

10. Hays EM, Duan W and Shigdar S: Aptamers and glioblastoma: Their potential use for imaging and therapeutic applications. Int J Mol Sci 18: 18, 2017.

11. Van den Abbeele A, De Corte V, Van Impe K, Bruyneel E, Boucherie C, Bracke M, Vandekerckhove J and Gettemans J: Downregulation of gelsolin family proteins counteracts cancer cell invasion in vitro. Cancer Lett 255: 57-70, 2007.

12. Livak KJ and Schmittgen TD: Analysis of relative gene expression data using real-time quantitative PCR and the 2(-Delta Delta C(T)) method. Methods 25: 402-408, 2001.
13. Seifabadi S, Vaseghi G, Javanmard SH, Omidi E, Tajadini M and Zarrin B: The cytotoxic effect of memantine and its effect on cytoskeletal proteins expression in metastatic breast cancer cell line. Iran J Basic Med Sci 20: 41-45, 2017.

14. Vitali E, Boemi I, Rosso L, Cambiaghi V, Novellis P, Mantovani G, Spada A, Alloisio M, Veronesi G, Ferrero S, et al: FLNA is implicated in pulmonary neuroendocrine tumors aggressiveness and progression. Oncotarget 8: 77330-77340, 2017.

15. Glaser J, Neumann MH, Mei Q, Betz B, Seier N, Beyer I, Fehm T, Neubauer H, Niederacher D and Fleisch MC: Macrophage capping protein CapG is a putative oncogene involved in migration and invasiveness in ovarian carcinoma. BioMed Res Int 2014: 379847, 2014.

16. Aevermann BD, Pickett BE, Kumar S, Klem EB, Agnihothram S, Askovich PS, Bankhead A III, Bolles M, Carter V, Chang J, et al: A comprehensive collection of systems biology data characterizing the host response to viral infection. Sci Data 1: 140033, 2014.

17. Welzel TM, Graubard BI, Zeuzem S, El-Serag HB, Davila JA and McGlynn KA: Metabolic syndrome increases the risk of primary liver cancer in the United States: a study in the SEER-Medicare database. Hepatology 54: 463-471, 2011.

18. Tomczak K, Czerwińska $\mathrm{P}$ and Wiznerowicz M: The Cancer Genome Atlas (TCGA): An immeasurable source of knowledge. Contemp Oncol (Pozn) 19 (1A): A68-A77, 2015.

19. Zhu WY, Hunag YY, Liu XG, He JY, Chen DD, Zeng F, Zhou JH and Zhang YK: Prognostic evaluation of CapG, gelsolin, P-gp, GSTP1, and Topo-II proteins in non-small cell lung cancer. Anat Rec (Hoboken) 295: 208-214, 2012.

20. Tonack S, Patel S, Jalali M, Nedjadi T, Jenkins RE, Goldring C, Neoptolemos J and Costello E: Tetracycline-inducible protein expression in pancreatic cancer cells: Effects of CapG overexpression. World J Gastroenterol 17: 1947-1960, 2011.

21. Van Impe K, Bethuyne J, Cool S, Impens F, Ruano-Gallego D, De WeverO, Vanloo B, Van Troys M,Lambein K, Boucherie C, etal: A nanobody targeting the $\mathrm{F}$-actin capping protein $\mathrm{CapG}$ restrains breast cancer metastasis. Breast Cancer Res 15: R116, 2013.

22. Westbrook JA, Cairns DA, Peng J, Speirs V, Hanby AM, Holen I, Wood SL, Ottewell PD, Marshall H, Banks RE, et al: CAPG and GIPC1: Breast cancer biomarkers for bone metastasis development and treatment. J Natl Cancer Inst 108: 108, 2016.

23. Li BK, Guo K, Li CY, Li HL, Zhao PP, Chen K and Liu CX: Influence of suppression of CapG gene expression by siRNA on the growth and metastasis of human prostate cancer cells. Genet Mol Res 14: 15769-15778, 2015.

24. Xiang G: Relationship between macrophage capping protein and gastric cancer cell's proliferation and migration ability. Beijing Da Xue Xue Bao Yi Xue Ban 49: 489-494, 2017 (In Chinese)

25. Ichikawa H, Kanda T, Kosugi S, Kawachi Y, Sasaki H, Wakai T and Kondo T: Laser microdissection and two-dimensional difference gel electrophoresis reveal the role of a novel macrophage-capping protein in lymph node metastasis in gastric cancer. J Proteome Res 12: 3780-3791, 2013.

26. Xing W and Zeng C: An integrated transcriptomic and computational analysis for biomarker identification in human glioma. Tumour Biol 37: 7185-7192, 2016.

27. Yun DP, Wang YQ, Meng DL, Ji YY, Chen JX, Chen HY and Lu DR: Actin-capping protein CapG is associated with prognosis, proliferation and metastasis in human glioma. Oncol Rep 39: 1011-1022, 2018.

This work is licensed under a Creative Commons Attribution-NonCommercial-NoDerivatives 4.0 International (CC BY-NC-ND 4.0) License. 